\title{
Factors affecting the selection of information sources of sustainable agricultural practices by Malaysian vegetable farmers
}

\begin{abstract}
Information is key in reducing the uncertainties of sustainable agricultural practices (SAPs). The objective of this study was to improve the understanding of the relationship between utilized informational sources and other key identified factors affecting Malaysian vegetable producers' choices. The findings of a multivariate probit model suggest that information sources are complementary. The choices for these sources are influenced by heterogeneity in access to credit, social network (member of farmers association), and farm settings (distance from farm to market, resource depletion issues, and geographical regions). Future promotion of SAPs should be delivered through the provision of quality content disseminated through the preferred information sources, which target potential users.
\end{abstract}

Keyword: Sustainable agricultural practices; Information sources; Communication behaviors; Extension service; Multivariate probit model 
